\title{
Valued learning experiences of early career and experienced high
}

performance coaches

Clifford J. Mallett ${ }^{\mathrm{a}}$, Steven B. Rynne ${ }^{\mathrm{a}, \mathrm{b}}$, Stephen Billett ${ }^{\mathrm{c}}$

${ }^{a}$ The University of Queensland, School of Human Movement Studies, Australia

${ }^{b}$ Australian Sports Commission, Canberra, Australia

${ }^{c}$ Griffith University, School of Education and Professional Studies, Australia

Corresponding Author:

Associate Professor Cliff Mallett

School of Human Movement Studies

St Lucia, Qld 4072

AUSTRALIA

Email Address: cmallett@uq.edu.au

In Physical Education and Sport Pedagogy 


\section{Valued learning experiences of early career and experienced high performance coaches}

Background and purpose: This paper attempts to move the discussion of high performance coach development from an examination of coaches' volume of experiences towards a consideration of the contribution of the learning experiences that coaches have reported throughout their careers. Furthermore, a discussion of proximal and distal guidance in the development of coaches was investigated. We examined the kinds of learning experiences within the framework of workplace learning and specifically the situated nature of learning and the view that learning occurs through social participation.

Method: Nineteen high performance coaches participated in this study, including 10 scholarship and nine mentor coaches. Participants rated a list of 14 developmental activities derived from empirical research on a seven-point Likert scale $(0=$ not used, $1=$ of little value, to $7=$ extremely valuable). Each participant coach rated the 14 (guided, unguided) activities in the first two years of their coaching career, middle two years, and final two years. To analyse the data and identify the key trends for both the scholarship and mentor coaches we examined statistical differences between scores for each of the sources the nonparametric Friedman test was used $(p<.01)$. Significant $\chi^{2}$ results were followed up with the Wilcoxon (two-tailed) T-test test $(p<.05)$ to identify statistically significant differences between scores at different time intervals.

Results: Three key findings emerged from these data: (i) reported increased valuing of a range of developmental experiences over time; (ii) temporal variance in the value of different learning sources at different stages of their careers; and (iii) an acknowledgement of the shift away from an emphasis on proximal learning sources for the mentor coach and the shift towards proximal sources for the scholarship coach.

Keywords: elite coach development; workplace learning; proximal learning, distal learning 
Practitioner summary: This research examined high performance coaches' learning and, specifically, the learning of early career and experienced coaches within a formalised programme of development. Three key findings emerged. First, these coaches increasingly valued multiple contributions to their learning as they progressed across their careers. This pattern can perhaps be explained through the issues of increased self-awareness, access, and explicit accelerated development. Second, the perceived value of learning experiences in relation to each other changed over the course of their careers. This suggests that a range of experiences is required which provides particular contributions to the development of both groups of coaches. Third, direct guidance took on a key role in the early careers of experienced and early career coach groups. Early career coaches seemed to benefit from this close guidance until such time their coaching confidence was enhanced sufficiently to seek alternative and more indirect sources of advice and contributions.

\section{Developing high performing coaches}

The ongoing development of sports coaches is key to sustaining and improving the quality of coaching and professionalisation (Mallett, Trudel, Lyle and Rynne 2009). However, the initial preparation and ongoing development of these coaches is somewhat unique when compared with many other occupations (Lyle, Mallett, Trudel and Rynne 2009). For instance, a distinctive feature of the initial preparation for coaching is that it occurs outside of tertiary education programmes such as those required for entry into many other occupations (e.g., teaching, medicine, and law). Learning is central to coach development (Armour 2010); however, learning is complex and might be understood from many perspectives (Hodkinson, Biesta and James 2008). Terms such as learning are also concerned with the nature of knowledge and how it is acquired (Mallett and Tinning in press). Moreover, the various ways of understanding 
learning reflects different underpinning philosophical beliefs (Jarvis 2004). Although learning theories can be broadly classified as behaviourist, cognitive, and constructivist (Brockbank and McGill 2007), an understanding of learning in this study is centred on how high performance coaches learn their craft in the workplace; that is, how these coaches learn on-the-job and beyond traditional formal preparation courses. The discourse on learning is replete with many unhelpful binaries (e.g., formal versus informal) that have the potential to limit thinking and investigation (Cairns and Mallcoh 2011); therefore, in this study there was stronger consideration of the integration of theories and models in the broad field of workplace learning that considered the importance of both individual and social learning dimensions (Billett 2006; Hodkinson et al., 2008) in high performance coach development.

Recent studies in coaching (e.g., Erickson, Côté and Fraser-Thomas 2007; Gilbert, Côté and Mallett 2006; Lynch and Mallett, 2006) have identified the salience of developing an understanding of the pathways or coaching trajectories that current high performance coaches have experienced; that is, they inform the field regarding patterns of experience in relation to quantities (e.g., number of hours invested by coaches) in becoming effective in the practice. Furthermore, there have been several studies reporting the major sources of learning for high performance (elite) coaches. These sources (in no particular order) included, on the job experience, experience as an athlete, personal reflection, observing other coaches, discussions with other coaches, working with other coaches, external consultants, professional reading, professional development, in-house programmes, tertiary study, watching television, previous occupations, and family and friends (e.g., Côté, Ericsson, and Law. 2005; Cushion, Armour and Jones 2003; Gilbert and Trudel 2005; Irwin, Hanton and Kerwin 2004; Jones, Armour and Potrac 2003; Rynne, Mallett and Tinning 2006). These data provide 
some insight into how many hours coaches invested in developing their craft prior to becoming a successful coach and also the varied sources of learning; but say little, if anything, about the quality of those learning experiences.

Indeed, there has been too little discussion of the patterns of learning experiences that might be considered as optimum to the development of effective coaching practices. It follows that this paper offers an attempt to move the discussion of coach development from an examination of current (inclusive of early career) high performance coaches' volume of experiences accumulated over time towards a consideration of the contribution of particular kinds of learning experiences that coaches have reported as being useful throughout their careers. Consequently, we examine the relative perceived value of varied experiences to high performance coach development. Secondly, we examine the role of coaches' personal agency and workplace affordances (social suggestion). Personal agency is concerned with what directs their intentional engagement in activities and learning; whereas, the relevant extent by which coaches (as individuals) are offered to participate in and learn through work tasks comprise workplace affordances (Billett 2006). Furthermore, as part of this elaboration both proximal (i.e., direct interpersonal) and distal (i.e., indirect) guidance by more experienced coaches in the development of the capacity is required to be an effective coach will also be discussed.

\section{Workplace learning}

The theories of workplace learning are characterised by some key features, including: (i) consideration of both individual and social dimensions of learning (e.g., Billett's [2006] notion of relational interdependence between individual and social agency); (ii) learning is an ongoing temporal process (rather than a product) consistent with Sfard's 
(1998) participation metaphor and Hager and Hodkinson’s (2009) notion of 'becoming' or emergence (non-linear); (iii) individual learning is shaped by social and other contextual factors (i.e., learning is 'situated'); and (iv) problematising current conceptions of learning (Hager 2011). Within the broad framework of theories of workplace learning, the writings of Billett (2001; 2004; 2006) have been generative in thinking about how coaches re-shape their coaching practises as they engage in that work. Specifically in this study, we examine the notion of relational interdependence between coaches’ engagement in coaching practice (individual agency and subjectivities) and the affordances of the coaching context (social suggestion) (Billett 2006).

It is suggested that the development of high performance coaching is influenced by the interdependence between the agentic engagement of coaches and the external structures and practices that exist in the circumstances where they practice and learn (Mallett 2010; Mallett, Rossi and Tinning 2008; Rynne et al. 2006; Rynne et al. 2010); however, little is understood about high performance coaching and its ongoing development. Cushion et al. (2003) highlighted the need for research into coaches' learning in the workplace, because of the insufficiency of available evidence. Anecdotal accounts and empirical research regularly feature in coaches’ reports of how much they have learned observing and/or working with other (generally more experienced) coaches (e.g., Bloom, Durand-Bush, Schinke and Salmela 1998; Cassidy, Jones and Potrac 2004; Cushion, Armour and Jones 2003; Jones, Armour and Potrac 2003; Layton 2002; Trudel and Gilbert 2006). These reports have led to calls for formalized (or at least more structured) mentoring programmes for coaches (e.g., Bloom et al. 1998; Dickson 2001). It is noteworthy that in many occupations, the workplace has been found to provide opportunities for authentic learning experiences as well as 
opportunities for new learning, and the potential re-making of work practices as well as the ability to observe and evaluate progress (see Billett 2001).

Coaches, like other workers, learn their craft through personal engagement in work activities, which are mediated through proximal and distal social guidance, cultural norms, practices, and values (Billett 2001). Billett uses some novel terms associated with learning and occupations that require some clarification. In terms of guidance, several terms are often used interchangeably to describe the influence of others when learning an occupation. These include: the terms mediated and guided that suggest the deliberate influence of another (e.g., mentor coach) in how a worker responds and engages in learning opportunities such as through coaching work (Mallett et al. 2009). Billett (2001) uses the term 'proximal guidance' to refer to such direct interpersonal guidance and support that fosters a shared understanding between coworkers (intersubjectivity). Nevertheless, much learning occurs outside of circumstances in which direct guidance is available and here, learning is likely to be largely self-directed. This kind of learning process might be deliberate (i.e., intentional, as in practice or effortful engagement) or incidental (i.e. unintended arising from unforeseen circumstances) (Mallett et al. 2009). The term 'distal guidance' (Billett 2001) has also been used to characterise the more indirect contributions of others and the physical world that together mediate individuals’ knowledge. Indeed, it seems that much of learning through practice of a range of kinds arises through observation and imitation.

\section{Purpose of inquiry}

The main purpose of the enquiry reported here is to examine the perceptions of high performance coaches regarding the value of various sources of learning to their 
development at different stages of their high performance coaching careers. In this study, research examining the personal histories of two groups of coaches involved in a formal mentoring programme were drawn upon: (i) one group of informants who are currently high performance coaches (assigned as mentor coaches); and (ii) those who have been identified as potential future high performance coaches (scholarship coaches). It is the insights from these two groups that form the key data for what is presented and discussed below.

\section{Method}

\section{Participants}

The findings reported here are part of a larger project examining the learning and mentoring of high performance sports coaches. Nineteen coaches voluntarily participated in this research as informants. They included 10 scholarship coaches (SC; seven male and three female) and nine mentor coaches (MC; eight male and one female). These coaches represent nine sports including six individual (rowing, canoe/kayak, BMX, gymnastics, swimming, yachting) and three team sports (football, basketball, netball).

The MCs in this study averaged 47 years of age (Range $=38-60)$ and most were tertiary educated (community college [n = 2], undergraduate [n = 4], Masters $[n=1]$ ). All MCs had played at the elite level in the sport they now coached $(M=14$ years, Range $=3-24)$ and had been coaching their sport for an average of 23 years (Range $=9$ 29). The MCs had generally been working at the elite level for many years ( $M=16$ yrs, Range $=3-24 y r s$ ). In comparison, the SCs were on average 33 years old (Range $=23-$ 41) and most were also tertiary educated (community college [n = 1], undergraduate [n = 3], Masters [n=2]). Like the mentor coaches they were similarly oriented to the elite 
level of sports with all but one of the scholarship coaches competing at the elite level in the sport they now coached. In fact, half of the group were ex-professional athletes in their respective sports. As might be expected, given the nature of the programme, the scholarship coaches had approximately half of the coaching experience of their mentors $(M=12$ years, Range $=2-20)$.

\section{Organisational context}

The Australian Sports Commission (ASC) is the primary national sports administration and advisory agency. At the time of the study, the Sports Coach and Official Section, was responsible for administering and supporting the accreditation (i.e., certification) of coaches and officials; and the National Coaching Scholarship Programme (NCSP). The key purpose of the NCSP was to assist in (a) the development of coaches who have been identified by their sports as potential high performance coaches, and (b) continuing professional development of current high performance coaches (Coaching and Officiating Unit 2008). The coaching scholarships were awarded for two years full-time or two years part-time depending on the terms of the application. Scholarship coaches received a remuneration package that included a stipend and professional development and education allowances. Since 1993, more than 220 coaches have completed a coaching scholarship under the NCSP (Coaching and Officiating Unit 2008).

\section{Procedure}

A University’s human ethics committee granted approval for the data gathering prior to commencing the study. Participants were identified and recruited through the Manager of the Coaching and Officiating Unit at the Australian Sports Commission. Scholarship and mentor coach participants, who were based in Canberra and Brisbane, were contacted for voluntary participation in this part of the project. A guide was sent to all 
participants at least seven days before their in-depth, face-to-face survey with advice about the rationale for the study, the use of data, issues regarding confidentiality, the participants’ rights, and the reasons for audio-taping the face-to-face survey. All participants were surveyed face-to-face and independently at their convenience.

\section{Survey}

Each participant coach independently engaged in an in-depth, face-to-face survey with the second author that lasted between 50 and 95 minutes. First, demographic data were collected. Second, to facilitate discussion and subsequent ratings of key sources of learning for high performance coaches, a list of 14 developmental activities was identified from the empirical literature (e.g., Côté et al. 2005; Gilbert and Trudel 2005; Irwin, Hanton and Kerwin 2004) and was modified based on pilot studies and previous research in the Australian context (Rynne et al. 2006). The list of developmental activities consisted of: on the job experience, experience as an athlete, personal reflection, observing other coaches, discussions with other coaches, working with other coaches, external consultants, professional reading, professional development, in-house programmes, tertiary study, watching television, previous occupations, and family and friends. Participants were also given the opportunity to suggest other activities they believed made significant contributions to their development. However, none were advanced. A seven-point Likert scale $(0=$ not used, $1=$ of little value, $7=$ extremely valuable) was used to determine NCSP coach perceptions regarding the value of a range of the aforementioned developmental activities.

The in-depth, face-to-face survey facilitated the verbalisation of rationales underpinning participants’ decision-making and on some occasions participants verbalised their thought processes, providing justifications for their ratings. So in 
addition to the researcher providing descriptions of the items to participants, the participants were also able to clarify their understanding and the researcher was able to provide further instruction and direction if required. The following are samples of the items and the kinds of instructions given to participants:

- On the job experience: learning from the time spent engaging in coaching activities. Usually referred to a 'learning by doing', or 'trial and error'.

- Reflection: This refers to the time spent thinking about your coaching. Reflection usually takes place at a time and setting removed from the coaching setting.

- Observing other coaches: This is time spent observing other coaches who you are not working directly with and with whom you have limited verbal interaction; it might be coaches of other clubs, states or countries and you might see them in training and/or competitions environments.

A potential concern with the items above is that there is a degree of overlap amongst them. Despite this and given the aims of the study, this was not felt to be an issue as they were derived from previous research and served their intended purpose of clarifying the coaches' views on how they had developed their craft throughout their careers. There was no assertion made about the independent validity of the categories, nor was there an attempt to make definitive claims regarding a hierarchy of learning sources. Rather, these activities and the subsequent ratings were used in this largely exploratory investigation to attempt to identify emerging themes and trends in the learning of this, so far, under-theorised vocational group (early career and experienced high performance coaches). 
In addition to rating the perceived contribution that each of the activities/sources made to the development of their capacities in recent times (the last two years), the mentor and scholarship coaches also retrospectively rated the perceived utility of these sources at the beginning of their coaching careers (the first two years) and the middle of their careers. The rating of these activities for their first two years and middle two years of coaching required the informants to recall events and experiences that occurred sometimes a decade or more in the past. Prior to collecting this data, the second author collected a raft of more verifiable information (e.g. years engaged in certain sports), which was proposed to facilitate the recall actual events and memories rather than inferences and reconstructions (Côté et al. 2005; Gilbert et al. 2006). Finally, it is important to note that because of the high variability in career length, not all coaches were able to complete all of the ratings (e.g., those with four or five years coaching experience could only complete ratings for the first two years and most recent two years and those with less than four years experience completed only the ratings for the first two years of the their coaching).

\section{Data Analyses}

The current and retrospective Likert scale ratings of each of the 14 activities were entered into a data spreadsheet and checked for accuracy. Basic descriptive statistics were generated (e.g., Mean, range) for the entire group, and for the MCs and SCs as separate groupings. To examine statistical differences between scores for each of the sources the non-parametric Friedman test was used $(p<.01)$. Significant $\chi^{2}$ results were followed up with the Wilcoxon (two-tailed) T-test test $(p<.05)$ to identify statistically significant differences between scores at different time intervals (T1 v T2; T2 v T3; T1 v T3). 


\section{Results}

Basic descriptive statistics were generated for the MCs and SCs are presented in Tables 1 and 2 respectively. Data presented in Tables 1 and 2 include: (a) most valued sources based on mean scores for each activity, (b) the ranking of each activity within each of the three time periods, and (c) the identification of those activities that were considered guided by another person (proximal). Overall, there were three main areas of interest that emerged from the data. The first related to the general trend for coaches to continue to use a wide range of sources to support their development as their careers progressed. This trend is somewhat counterintuitive as will be explained in the discussion section. The second area relates to the value of certain developmental activities in relation to other developmental activities. The final theme relates to the proximal and distal nature of the sources valued by the coaches.

\section{A. Most valued activities}

In analysing data reporting the contributions of the varying sources of learning for the coaches, the following categorisations were noted: those sources with mean values of 5.5 or above were deemed to be extremely valuable, those from $4.0-5.4$ were deemed to be valuable, 2.5 - 3.9 of some value, and less than 2.5 of limited value. These categorisations are delineated by different shades of colour in the tables.

\section{Mentor coaches}

As indicated in Table 1, the most valued sources in the first two years were (in ranked frequency order): on the job experience and experience as an athlete (both $>5.5$ ). In the second two years of their career the most valued sources reported were (in ranked frequency order): on the job experience, experience as an athlete, reflection, and 
tertiary study (all $>5.5$ ); whereas in the last two years MCs reported the most valued sources to be (in ranked frequency order): on the job experience, reflection, consultants, and discussions with others (all > 5.5).

\section{Scholarship coaches}

As indicated in Table 2, the most valued sources in the first two years and in the second two years were (in frequency ranking order): on the job experience and experience as an athlete (both $>5.5$ ), as indicated in Table 2. In the last two years, SCs reported the most valued sources to be (in frequency ranking order): discussions with others, working with others, on the job experience, reflection, observing others, consultants, experience as an athlete, professional reading, professional development, and in-house programmes (all $>5.5)$.

\section{Trends for activities over time}

The results of the non-parametric Friedman (ANOVA) test found significant differences $(p<.01)$ between mean scores at the three time points (T1 v T2; T2 v T3; T1 v T3) for some sources. These significant results were followed up with the Wilcoxon T-test test $(p<.05)$ to identify statistically significant differences between scores at each of the three time points. In other words, was there a shift in the reported use of a particular source of knowledge throughout their coaching career to date? For the MCs $(n=9)$ the results of the Wilcoxon T-test indicated that only other sources increased over time and for each time interval. Reflection increased from the first two years to the middle two years and from the first two years to the last two years. For the SCs $(n=9)$, the results of the Wilcoxon T-test indicated that three sources increased over time for each time interval: reflection, consultants, and previous occupations. The following sources increased from the second two years to the third two years and from the first two years 
to the last two years: observing others, tertiary study, professional reading, in-house programmes, and professional development. There were no significant differences for on the job experience, working with others, discussions with others, watching TV, family and friends, experience as an athlete, or other.

MCs' increased valuing of all development activities

From the Mentor Coaches data, there was identified a general trend of increasing value placed on a wide variety of sources as their careers progressed. More specifically, for all activities except experience as an athlete, there was an increase in the reported value from the first two years of their careers to the most recent two years of their careers (i.e., the vast majority of activities were deemed to be more valuable as their careers progressed). However, it should be noted that for some activities this increase in value was very minor and that for others, there was a peak in reported value in the middle two years of coaches' careers (e.g., professional reading and tertiary study). Finally, in addition to discussing the contribution of each activity in relation to its reported value over time, it was possible to review them in relation to the reported worth of other activities in the same time periods.

\section{SCs' increased valuing of all development sources}

As with the MCs, there was a general trend of increasing value placed on a wide variety of sources as the careers of the SCs progressed. For the majority of activities, there was an increase in the reported value from the first two years of the SCs' careers to the most recent two years of their careers (i.e., most activities were deemed to be more important as their careers progressed). The exceptions were experience as an athlete, family and friends and on-the-job experience. It should be noted that while on-the-job experience showed a very minor decline from the first two years of coaching to the last two years 
of coaching, its overall value rating was extremely high (i.e., Mean $>6$ across all time periods). Unlike the MCs, none of the SCs' activities showed a peak in value during the middle two years of their careers. Finally, like the MCs it was possible to consider the worth of each activity in relation to its reported value over time, as well as review them in relation to the reported worth of other activities concurrently.

\section{B. Reported value of developmental activities}

MCs'valuing of developmental activities

There was some temporal variance in the relative value of the various developmental activities. The most obvious trend related to on the job experience. This activity was rated very highly by the MCs for the contribution it made to their development. Indeed, as can be seen in Table 1, on the job experience (i.e., without the assistance of others) was consistently rated as being of utmost importance at all time points. As well as being most valuable, this was also shown to be the most stable of the developmental value ratings (along with the poorly rated in-house programmes).

Another observable trend related to the movement of experience as an athlete. This activity, while thought to be valuable in the beginning and mid-point of the MC's careers was deemed to be less important as their careers progressed (as reported in the most recent two years). Showing even greater decline in importance than previous athletic experiences were professional development (i.e., developmental activities and courses outside of formal tertiary awards - often provided by the national or state sporting organisation) and professional reading (i.e., reading done outside of formal tertiary study - including sport-specific journals and magazines as well as books and newspapers) (see Table 1). In contrast, reflection was reported to be increasingly 
important (as a source and ranking) for the MCs as their careers progressed (see Table 1).

\section{SCs’ valuing of developmental activities}

For the SCs, consultants and personal reflection were considered to be increasingly important for their development as their careers progressed (Table 2). Similarly, and like the MCs, the SCs reportedly valued on the job experience highly throughout their careers. The reported rank of this source in relation to other sources was also relatively stable throughout their careers. Unlike the MCs, however, the SCs reported that working with and talking with other coaches became relatively more important than learning by doing in the most recent two years of their coaching (Table 2). Talking with other coaches (discussions with others) was also stable throughout their careers to date (in relation to other activities) (Table 2). While we will discuss this in more detail later in this paper, it should be noted that the nature of the NCSP meant that this result was not entirely unexpected.

Again, like the MCs, the SCs valued experience as an athlete highly in the first two and middle two years of their careers. However, the relative importance of this source decreased as their careers progressed (also note that the mean rating of this source actually increased in the most recent two years compared with mid-career).

While the relative ranking and value of experience as an athlete and family and friends experienced a negative trend, consultants, in-house programmes and reflection all showed increases in value relative to other activities as the SC's careers progressed.

\section{Proximal and distal guidance}

In Tables 1 and 2, the activities that were considered to be proximal in the nature of their guidance are marked with a 'P'. Activities were designated as proximal if there 
was a more experienced partner who was in regular contact and who provided scaffolded activities. In consideration of the nature of the activities, the MCs valued less the more proximal sources, compared with the distal sources, in the middle of their careers. In the first two years of coaching, the MCs reported that four of the top five most valuable sources were proximal in nature. These proximal sources declined in the middle two years (one of the top five) while the most recent two years saw an increase in the proximal nature, albeit a different source (consultants). Regarding the nature of the activities discussed by the SC, and as alluded to above, proximal sources (relative to more distal sources) were deemed to be very important to SC development in their most recent two years of coaching (the majority of which was spent in the NCSP).

What should be noted and will be reinforced in the subsequent discussion of these results is that while these ratings are perceived to be an accurate reflection of how valuable these sources have been in the development of these coaches it does not report what the high performance coaches considered optimal for their development. In other words, it does not necessarily represent the ideal or preferred way in which they developed.

\section{Discussion}

The athletic and coaching histories are seen as developmental trajectories, which arise through access to particular kinds of experiences and how these individuals have engaged with and learn from them. As mentioned in the results section, there were three key findings that emerged from these data. The first refers to the reported increased valuing of a range of developmental activities over time. The second considers the temporal variance in the value of different learning sources; and the final theme relates to the shift away from an emphasis on proximal learning sources for the MC and the 
shift towards proximal sources for the SC.

\section{A. Increasing perceived value of all development sources}

As noted above, overall, there was a general trend of increased valuing of a wide variety of learning sources. This trend is somewhat counterintuitive. It may be argued that as coaches become more fully engaged in the coaching process (i.e., moving to full-time employment as a coach), their work becomes more demanding and they would have less opportunity to engage with a range of sources. Similarly, it might be assumed that as coaches progressed in their careers, they may become more adept at identifying the most valuable sources, therefore making use of only a select few activities to further develop their craft. Perhaps coaches look for multiple sources for information to support the efficacy of their decision-making in challenging and critical situations.

Three possible explanations for the reported trend are proposed. First, as coaches progress in their careers they are likely to become increasingly aware of the range of activities that may contribute to their development (i.e., they have a greater awareness of what activities are on offer and they avail themselves of a greater range). For example, one of the football coaches spoke of how he only realised in his second year of employment as a head coach that he was eligible for travel funds to visit international clubs. Second, as coaches become increasingly immersed in the culture of their sport, and in high performance sport more generally, they begin to gain access to a range of sources that they previously did not have access to (due to funding or other issues e.g., consultants and in-house programmes). For example, the BMX coach described that since becoming employed by the national body he has access to sport science and sport medicine support personnel (something that he had never had access to in the past). Third, the aim of the NCSP is to accelerate the development of the SCs. In this way, the 
SCs are likely to have been given greater access and had greater awareness of workplace affordances through this programme in the most recent two years of their careers. For example, the scholarship coaches are funded to engage with tertiary study and this was an opportunity that the basketball coach did not know even existed.

\section{B. Reported value of developmental activities}

\section{Learning from doing}

As noted in the results section, for both the MCs and SCs, learning from on the job experience was considered extremely important throughout their careers. Several scholars have discussed the efficacy of learning from previous coaching experiences (Erickson, Bruner, MacDonald and Côté 2008; Gilbert et al. 2006; Lynch and Mallett 2006; Trudel and Gilbert 2006; Wright, Trudel and Culver 2007). What is not clear is whether this circumstance represents an ideal or preferred situation or whether it reflects the isolated nature of coaching work (i.e., there may be few other ways to learn other than by doing it without guidance). Erickson and colleagues (2008) noted discrepancies between the actual and preferred sources of learning with the developmental coaches often reporting learning by doing as an actual source of knowledge (58.4\%) but less as a preferred source (37.3\%). Given that on the job experience was rated as being extremely valuable for the NCSP coaches and that it was relatively stable in relation to other sources of development, it might be assumed that of the sources available to the MCs and SCs that it is one of the most preferred. This preference for learning by doing reflects the importance of authentic learning opportunities such as those that can be found in the actual circumstances of occupational practice and its enactment. 


\section{Learning from athletic experience}

It has been widely recognized that, with a few exceptions, high performance coaches have competed in the sport that they currently coach (e.g. Abraham, Collins and Martindale 2006; Bloom et al. 1998; Côté 2006; Cushion et al. 2003; Jones et al. 2003; Sage 1989). Regarding this cohort, the value placed on previous athletic experiences to coaching development reportedly declined greatly as the careers of the MCs and SCs progressed. This suggests that while previous experience as an athlete was important at the beginning (and to a certain extent in the middle) of their careers, there are more valuable sources that were capable of being more generative in their current high performance work as their careers progressed. This shift may reflect the transition from a dominant athlete to coach identity.

\section{Learning from others}

Cushion et al. (2003) reported that the technical aspects of coaching and coaching culture are often acquired through observing and listening to more experienced coaches. Not surprisingly, interactions with other coaches were generally well regarded by the MCs albeit less so as their careers progressed. The positions held by these coaches as their careers progressed often meant that they were identified as the best coach in their club, region, state, and in a number of cases the best in the country. For this reason, there may have been less people they felt were capable helping them to develop their coaching as their careers progressed. Given that the contexts in which these participants coached became increasingly contested (i.e., towards more isolated, elite coaching settings) it may also be that these coaches were guarded and unlikely to be revealing areas of perceived deficit or weakness to coaches in subordinate positions or to those that their athletes were competing against. Previous research has noted that the theme of 
isolation pervades much of the discussion of the sources of learning coaches access (Rynne \& Mallett, 2012).

Working directly with other coaches showed an opposite trend for the SCs in that it was reported to be of greater value more recently in their work. This may be because of the increased opportunity to work with others as their careers progressed. Although it comprises a number of discrete components (e.g., tertiary study, professional development blocks) the NCSP is essentially a structured mentoring programme. The high rating of working with other coaches in the most recent two years may be an indication of the utility of this programme. The fact that it is working "with" other coaches rather than "against" provides some indication of why it was held to make contributions to coach development even as the competitive nature of the work increased. It is for reasons such as this that there have already been a number of calls for formalized (or at least more structured) mentoring programmes for coaches (e.g., Bloom et al. 1998; Dickson 2001).

\section{Tertiary study}

While the values for tertiary study in Tables 1 and 2 include the scores from coaches who have done study in any field, for those who had attained degrees in sport-related fields such as sports science or human movement studies (4 SC and 4 MC), their assigned ratings over the three time periods were: 4.6 (4.0 SC, $5.3 \mathrm{MC}$ ), 5.9 (4.7 SC, 6.8 MC) and 6.3 (6.8 SC, 5.8 MC) (out of 7). Given that a number of the coaches had not begun or finished their qualifications in the first two years of their coaching, we might focus on the perceived value of tertiary study in the middle two years for the mentor coaches (i.e., 6.8 out of 7), and the most recent two years of coaching for both groups (i.e., 6.3 out of 7). These levels of perceived value are comparable to that assigned to 
learning on the job (6.3 for the middle two years and 6.5 for the most recent two years), a source acknowledged as being of utmost importance (Erickson et al. 2008; Gilbert et al. 2006; Lynch and Mallett 2006; Trudel and Gilbert 2006; Wright et al. 2007). These results indicate that formal tertiary study that is relevant and authentic to the coach's chosen sport is extremely valuable in developing coaches’ craft (Mallett and Dickens 2009). This conclusion serves to strengthen the case made by other researchers who have identified university-based academic training as a very useful component of coach development (Gilbert et al. 2006).

\section{Proximal and distal guidance for work}

\section{Mentor coaches}

The top source of learning throughout the career was on the job experience (distal). Nevertheless, it is noteworthy that in the first two years of coaching four of the top five sources were considered proximal, which suggests a preference for direct guidance early in their career. This may represent an inclination for authentic learning sources and/or perhaps it might reflect the socially isolated nature of coaching work throughout a career. In the middle two years the highest-ranking proximal source (working with others) was fifth. This finding indicates the increasingly problematic nature of finding proximal sources of development, which might be due to access or preference issues. For the most recent two years these MC favoured more proximal sources. Specifically, consultants were reported as influential sources of learning support. An increase in accessing consultants might be attributable to dealing with specific issues that might require the need for confidentiality or seeking advice from neutral professionals. It is noteworthy that the MC informants were generally agentic (i.e. proactive and active) in approaching and sometimes employing these personnel, which probably served to 
enhance the value of that relationship through mutual trust and respect. Moreover, the increased access to consultants was made possible because these MC were likely to access additional funds. Finally, as MCs progressed in their careers the sense of increased coaching efficacy might promote agency in accessing alternative and varied sources of learning

\section{Scholarship coaches}

Compared with the MC, to date the SCs had greater access to of proximal guidance throughout their careers. The worth of working with, discussing and observing other coaches continues to be sustained as reported by these early career high performance coaches which can be taken as an indication of the perceived efficacy of the NCSP - the aim of the NCSP is to improve proximal guidance of the coach through a structured mentoring programme. Nevertheless, SCs assist MCs rather than leading the squads and teams they work with. They are subordinate to the MCs, and therefore may have limited access to full engagement in the coaching process and to hands on coaching practice. In other words, there may be less opportunity to develop through on the job experience and therefore the most accessible means becomes discussions with and working with other coaches.

\section{Summary}

\section{Developing and sustaining effective coaching skills}

Learning for the complex and challenging work of high performance coaches is difficult but necessary for improved coaching performance (Cushion et al. 2003; Rynne et al. 2010). Research examining how high performance coaches engage in learning their craft is necessary to inform coach developers. In this programme of research, it is 
considered important to identify factors that both foster and interfere with that learning and subsequent development (Mallett et al. 2009; Rynne et al. 2010). Hence, we examined high performance coaches' learning and, specifically, the learning of early career and experienced coaches within the NCSP.

Three key findings emerged from the data reported here. First, these coaches increasingly valued multiple contributions to their learning as they progressed across their careers. This pattern can perhaps be explained through the issues of arising selfawareness, access, and explicit accelerated development. An implication of this first finding for coach developers is the importance of providing access to a broad range of learning opportunities, such as those listed above. Second, these high performance coaches reported temporal variance of valued sources. It is significant that across coaches' careers access to different sources of learning at varying stages of development highlights both the complexity of development and the need for coach developers to cater for this variance. It also suggests that a range of experiences is required which provides particular contributions to their development and that even the same category of experience (e.g., on-the-job learning) may well take quite a different form between that of the early career and the more experienced. For instance, the more experienced coach may well engage more in monitoring and appraising what is occurring, whereas a less experienced coach might be more concerned with attempting to comprehend what is occurring. So, this emphasises that beyond the provision of experiences, it is how individuals at different points in the trajectory of development come to engage with particular kinds of experiences. Third, proximal sources took primacy in the early careers of MCs and SCs in this accelerated NCSP. Early career high performance coaches seemed to benefit from this close guidance until such time 
their coaching efficacy was enhanced sufficiently to agentically seek alternative and more distal sources of advice and contributions.

The overall contribution of this research is to foster a move away from a quantitative to a more qualitative evaluation of learning sources for high performance coaches. However, these findings are qualified in many ways. It is important to acknowledge several limitations of this inquiry. First, whilst the creation of these categories of learning sources was informed by previous research, there is noticeable practical and conceptual overlap. Our intention was not make definitive claims about the categories per se but to extend the research beyond quantitative considerations. We also appreciate the limitations of such a small and purposive sample and that the research design was retrospective. Nevertheless, this research can provide some guidance for future research to inform high performance coach development. Therefore, future research might examine coach development programme efficacy, and specifically, their impact on practice and athlete outcomes. Furthermore, future research might prospectively examine what learning sources are available and how coaches agentically engage or do not engage in these affordances. To advance the field it might be necessary to shift scholarship from established binaries (e.g., informal versus formal) to less restrictive views of how high performance coaches learn in the workplace - this paper was an attempt to initiate that shift from such unhelpful binaries. Finally, research might consider the notion of identity as coaches make the transition from athlete to coach to experienced coach. 


\section{References}

Abraham, A., D. Collins, and R .Martindale. 2006. The coaching schematic: Validation through expert coach consensus. Journal of Sports Sciences 24, no. 6: 549-564.

Armour, K.M. 2010. The learning coach...the learning approach: Professional development for sports coach professionals. In Sports coaching: Professionalism and practice, eds J. Lyle and C. Cushion, 153-164. London: Elsevier.

Billett, S. 2001. Learning throughout working life: Interdependencies at work. Studies in Continuing Education 23(1): 19-35.

Billett, S. 2004. Co-participation at work: Learning through work and throughout working lives. Studies in the Education of Adults 36, no. 2: 190-205.

Billett, S. 2006. Relational interdependence between social and individual agency in work and working life. Mind, Culture and Activity 13, no. 1: 53-69.

Bloom, G.A., N. Durand-Bush, R.J. Schinke and J.H. Salmela. 1998. The importance of mentoring in the development of coaches and athletes. International Journal of Sport Psychology 29: 267-281.

Brockbank, A. \& McGill, I. Facilitating reflective learning in higher education. London: McGraw-Hill Education.

Cairns, L. and M. Malloch. 2011. Theories of work, place and learning: New directions. In The SAGE handbook of workplace learning, eds M. Malloch, L. Cairns, K. Evans, and B.N. O’Connor 3-16. London: SAGE.

Cassidy, T., R.L. Jones and P. Potrac. 2004. Understanding sports coaching: The social, cultural and pedagogical foundations of coaching practice. London: Routledge.

Coaching and Officiating Unit. 2008. National Coaching Scholarship Program - NSO guidelines 2008 Final. Canberra: Australian Sports Commission.

Côté, J. 2006. The development of coaching knowledge, International Journal of Sports Science \& Coaching 1, no. 3: 217-222.

Côté, J., K.A. Ericsson, and M.P. Law. 2005. Tracing the development of athletes using retrospective interview methods: A proposed interview and validation procedure for reported information. Journal of Applied Sport Psychology 17: 1-19.

Cushion, C.J., K.A. Armour and R.L. Jones. 2003. Coach education and continuing professional development: Experience and learning to coach. QUEST 55: 215230. 
Dickson, S. 2001. A preliminary investigation into the effectiveness of the national coach accreditation scheme. New South Wales: Australian Sports Commission.

Erickson, K., M.W. Bruner, D.J. MacDonald and J. Côté. 2008. Gaining insight into actual and preferred sources of coaching knowledge. International Journal of Sports Science \& Coaching 3, no. 4: 527-538.

Erickson, K., J. Côté and J. Fraser-Thomas. 2007. Sport experiences, milestones, and educational activities associated with high-performance coaches' development. The Sport Psychologist. 21: 302-316.

Gilbert, W., J. Côté and C. Mallett. 2006. The talented coach: Developmental paths and activities of successful sport coaches. International Journal of Sport Science and Coaching 1, no.1: 69-76.

Gilbert, W. and P. Trudel. 2005. Learning to coach through experience: Conditions that influence reflection. Physical Educator 62, no. 1: 32-43.

Hager, P. 2011. Theories of workplace learning. In The SAGE handbook of workplace learning, eds M. Malloch, L. Cairns, K. Evans, and B.N. O’Connor, 17-31. London: SAGE.

Hager, P. and P. Hodkinson. 2009. Moving beyond the metaphor of transfer of learning. British Educational Research Journal 35, no. 4: 619-638.

Hodkinson, P., G. Biesta, \& D. James. 2008. Understanding learning culturally: Overcoming the dulaism between social and individual views of learning. Vocations and Learning 1, no. 1: 27-47.

Irwin, G., S. Hanton and D.G. Kerwin. 2004. Reflective practice and the origins of elite coaching knowledge. Reflective Practice 5, no. 3: 425-442.

Jarvis, P. 2004. Adult education and lifelong learning: Theory and practice ( $3^{\text {rd }}$ edition). London: Routledge.

Jones, R.L., K.M. Armour and P. Potrac. 2003. Constructing expert knowledge: A case study of a top-level professional soccer coach. Sport, Education and Society 8: 213-229.

Layton, R. 2002. Making mentors. Canberra: Australian Sports Commission.

Lyle, J., Mallett, C. J., Trudel, P., \& Rynne, S. B. 2009. Formal vs. informal coach education: A response to commentaries. International Journal of Sports Science and Coaching 4, no.3: 359-364. 
Lynch, M. and C. Mallett. 2006. Becoming a successful high performance track and field coach. Modern Athlete and Coach 22, no. 2: 15-20.

Mallett, C.J. 2010. High performance coaches' careers and communities. In Sports coaching: Professionalism and practice, eds J. Lyle and C. Cushion, 119-133. London: Elsevier.

Mallett, C.J., P. Trudel, J. Lyle, and S.B. Rynne. 2009. Formal vs. informal coach education. International Journal of Sports Science \& Coaching 4, no. 3: 325334.

Mallett, C.J. and S. Dickens. 2009. Authenticity in formal coach education: Online postgraduate studies in sports coaching at The University of Queensland. International Journal of Coaching Science 3, no. 2: 79-90.

Mallett, C.J. and R. Tinning. In press. Coaching research and the philosophy of knowledge. In Research methods in sports coaching, eds L. Nelson, P. Potrac and R. Groom. London: Taylor Francis.

Mallett, C., T. Rossi and R. Tinning. 2008. Relational Interdependence between agency and affordances in how high performance coaches learn. Paper presented at 2008 Association Internationale des Ecoles Superieures d'Education Physique (International Association for Physical Education in Higher Education) Congress, January 21-24, Sapporo: Japan.

National Board of Employment Education and Training. 1994. Workplace learning in the professional development of teachers: Commissioned report No. 24. Canberra: Australian Government Publishing Services.

Rynne, S.B. and C.J. Mallett. 2012. Understanding and learning high performance coaches’ work. Physical Education and Sport Pedagogy 17, no. 5: 507-523.

Rynne, S.B., C.J. Mallett and R. Tinning. 2006. High performance sport coaching: Institutes of sport as sites for learning. International Journal of Sport Science \& Coaching 1, no. 3: 223-233.

Rynne, S., C.J. Mallett and R. Tinning. 2010. The learning of sport coaches in high performance workplaces. Sport, Education and Society 15: 331-346.

Sage, G.H. 1989. Becoming a high school coach: From playing sports to coaching. Research Quarterly for Exercise and Sport 60, no. 1: 81-92.

Sfard, A. 1998. On two metaphors for learning and the dangers of choosing just one. Educational Researcher 27, no. 2: 4-13. 
Trudel, P. and W. Gilbert. 2006. Coaching and coach education. In The handbook of physical education, eds D. Kirk, D. Macdonald and M. O'Sullivan, 516-539. London: Sage.

Wright, T., P. Trudel and D.M. Culver. 2007. Learning how to coach: The different learning situations reported by youth ice hockey coaches. Physical Education and Sport Pedagogy 12, no. 2: 127-144. 
Table 1. Rankings of the Means for perceived developmental value of activities in the first two, middle two and most recent two years of the MCs' careers $(n=9)$

\begin{tabular}{|c|c|c|c|c|c|}
\hline \multicolumn{6}{|c|}{ NCSP Mentor Coaches } \\
\hline $1^{\text {st }} 2$ Years & & Middle 2 years & & Most recent 2 years & \\
\hline 1. On the job experience & (6.1) & 1. On the job experience & $(6.4)$ & 1. On the job experience & $(6.4)$ \\
\hline 2. Experience as an athlete & (5.9) P & 2. Experience as an athlete & (6.1) & 2. Reflection & (6.2) \\
\hline 3. Observing others & (5.0) P & 3. Reflection & $(5.6)$ & 3. Consultants & (5.8) P \\
\hline 4. Working with others & (4.2) P & 3. Tertiary study & $(5.6)$ & 4. Discussions with others & (5.7) $\mathrm{P}$ \\
\hline 5. Family and friends & (3.8) P & 5. Working with others & (5.3) P & 5. Experience as an athlete & $(5.2)$ \\
\hline 5. Professional development & (3.8) & 6. Observing others & (5.2) P & 6. Observing others & (5.1) P \\
\hline 5. Professional reading & (3.8) & 7. Discussions with others & (5.1) P & 7. Working with others & (5.0) P \\
\hline 8. Discussions with others & (3.7) $\mathrm{P}$ & 8. Professional development & $(5.0)$ & 8. Family and friends & (4.8) P \\
\hline 8. Reflection & (3.7) & 9. Professional reading & $(4.9)$ & 9. Tertiary study & $(4.7)$ \\
\hline 10. Tertiary study & (3.5) & 10. Family and friends & (4.8) P & 10. Previous occupations & $(4.4)$ \\
\hline 11. Consultants & (2.9) $\mathrm{P}$ & 11. Consultants & (4.4) P & 11. Professional development & $(4.2)$ \\
\hline 12. Watching TV & $(2.6)$ & 11. Previous occupations & $(4.4)$ & 12. Professional reading & (4.1) \\
\hline 13. In-house programmes & (1.6) & 13. In-house programmes & (3.8) & 13. In-house programmes & (3.8) \\
\hline 13. Previous occupations & (1.6) & 14. Watching TV & (3.4) & 14. Watching TV & (3.6) \\
\hline
\end{tabular}

Note. Value of developmental activity (little value $=1$, extremely valuable $=7$ ); Nature

of the source ( $\mathrm{P}=$ predominately proximal) 
Table 2. Rankings of the Means for perceived developmental value of activities in the first two, middle two and most recent two years of the SCs' careers $(n=9)$

\begin{tabular}{|c|c|c|c|c|c|}
\hline \multicolumn{6}{|c|}{ NCSP Scholarship Coaches } \\
\hline \multicolumn{2}{|l|}{$1^{\text {st }} 2$ Years } & \multicolumn{2}{|l|}{ Middle 2 years } & \multicolumn{2}{|l|}{ Most recent 2 years } \\
\hline 1. On the job experience & $(6.7)$ & 1. On the job experience & $(6.1)$ & 1. Discussions with others & (6.8) $P$ \\
\hline 2. Experience as an athlete & $(6.6)$ & 2. Experience as an athlete & $(6.0)$ & 2. Working with others & (6.7) $\mathrm{P}$ \\
\hline 3. Discussions with others & (4.7) P & 3. Discussions with others & (5.3) P & 3. On the job experience & (6.4)P \\
\hline 3. Family and friends & (4.7) P & 4. Observing others & (5.2) P & 3. Reflection & $(6.4)$ \\
\hline 5. Working with others & (4.2) $\mathrm{P}$ & 5. Working with others & (5.0) P & 5. Observing others & (6.3) $\mathrm{P}$ \\
\hline 6. Observing others & (4.1) P & 6. Reflection & $(4.4)$ & 5. Consultants & (6.3) P \\
\hline 7. Reflection & (3.5) & 7. Professional reading & (3.8) & 7. Experience as an athlete & $(6.2)$ \\
\hline 8. Professional reading & $(3.2)$ & 8. Watching TV & (3.7) & 8. Professional reading & $(5.8)$ \\
\hline 9. Watching TV & $(3.0)$ & 9. Family and friends & (3.0) P & 8. Professional development & $(5.8)$ \\
\hline 10. Professional developme & $(1.6)$ & 10. Consultants & (2.8) P & 10. In-house programmes & $(5.7)$ \\
\hline 11. Tertiary study & $(1.3)$ & 11. Previous occupations & $(2.7)$ & 11. Tertiary study & $(5.0)$ \\
\hline 12. Consultants & $(0.9) \mathrm{P}$ & 12. Professional developme & $(2.4)$ & 12. Watching TV & $(4.7)$ \\
\hline 13. Previous occupations & $(0.8)$ & 13. In-house programmes & $(2.3)$ & 13. Previous occupations & $(4.0)$ \\
\hline 14. In-house programmes & $(0.7)$ & 14. Tertiary study & $(2.0)$ & 14. Family and friends & (3.9) $\mathrm{P}$ \\
\hline
\end{tabular}

Note. Value of developmental activity (little value $=1$, extremely valuable $=7$ ); Nature of the source $(\mathrm{P}=$ predominately proximal) 